\title{
Research of the Application of Task Teaching Approach on Basic English
}

\author{
Wenjuan Yang \\ Wuhan Huaxia University of Technology, Wuhan, Hubei, 430000
}

Keywords: task teaching approach; Basic English; application study

\begin{abstract}
This paper introduces the theory of task teaching method, analyzes the problems in the application of task teaching method to middle school English teaching, discusses the effective strategies of task teaching method in middle school English teaching, and puts forward task design in English teaching in middle school.
\end{abstract}

\section{Introduction}

At the turn of the century, foreign language teaching developed rapidly. Its research has also shifted from language ontology and teaching materials to learner subjects, especially the complex internal and external factors that influence learners, learners' psychological processes and cognitive systems. The learner's biological mechanism and cognitive system will become the focus and development trend of language and foreign language teaching research in the new century. Therefore, foreign language teaching should be changed from the traditional concept of teacher-centered to the new concept of student-centered autonomous learning. It has been accepted by most foreign language teachers. Traditional teaching often focuses on the teaching of knowledge and the explanation and operation of language. It neglects the cultivation of students' abilities and the improvement of their overall quality. Because of the long-term influence of "exam-oriented education", the content of examinations has become the focus of teaching. However, in addition to having good professional qualities and good self-study habits, talents in the 21st century should also have the ability to compete, unite and collaborate, manage and coordinate, communicate, and innovate, as well as perseverance, perseverance, and happiness. Helping people, the good qualities of kindness and love. These are all ignored or ignored by traditional teaching. Today, in the course of advocating capacity-building and quality education, the student-centered education concept has been deeply rooted in people's minds. Many colleges and universities under the guidance of this idea have carried out reforms from the syllabus to teaching materials and teaching methods. The Task-based Approach, also known as the Activities Based Approach and the Group Learning Method (the author does not make a special distinction in this article), originated from N.S. Prabbu in Bangkad in India in the 1970s. Seoul conducted a communicative perspective teaching experiment. He organized the learning content into communication tasks, allowing students to learn through the activities of those communicative tasks. This method catalyzes students' meaningful use of language, creates a supportive environment conducive to language learning, and acquires internalization. At the same time, it cultivates their ability and awareness in communication, management, collaboration, and innovation as well as the spirit of cooperation in solidarity and friendship. For learners, it can eliminate anxiety, encourage bold risks, promote communication, and create a positive atmosphere in the classroom to help them learn from each other. The task teaching method emphasizes that the student is the main body of learning, fully mobilizes the subjective initiative of the students, conforms to the laws of language teaching, and also conforms to the new trend of English teaching. Therefore, while studying the new teaching reform methods both at home and abroad, the author combines the teaching experience of the students with the actual situation of the students and applies the task teaching method to college English teaching to explore a way to not only impart knowledge but also strengthen the cultivation of students' practical ability. And improve the overall quality of education reform. 


\section{The Difference between Traditional Teaching Methods and Task Teaching Method}

In teaching, if only traditional teaching is used, it will help students to form a knowledge structure and system in a short period of time, and it is easy to monitor the entire teaching process. However, in terms of cultivating goals, traditional teaching only focuses on imparting knowledge, not focusing on the cultivation of professional abilities, and is not conducive to the growth of creative talents with innovative thinking and innovative capabilities. In the teaching process, it generally pays more attention to how to teach and how to ignore students' learning. The main point of knowledge is to remember by rote, which is not conducive to mobilizing the students' enthusiasm for learning. The way of thinking formed under the guidance of this traditional education can no longer meet the needs of students' development and society, and cannot meet the needs of the development of the times. In traditional pedagogy, the relationship between teachers and students is representative of the following two: the relationship between active and passive acceptance, and the relationship between the main aspects (teachers) and secondary aspects (students). The reform of the relationship between teachers and students in traditional teaching is based on the above two relationships. For example, change students' passive acceptance into active acceptance, change students' secondary aspects as the main aspect, and explore and try out some new teaching modes. However, these reforms did not grasp the essence and did not accurately describe the relationship between teachers and students in teaching. In fact, "active" and "passive", "main aspects" and "secondary aspects" are not fixed in the entire teaching process, but are constantly changing with the change of specific circumstances. Therefore, the use of "proactive professor" and "passive acceptance", "main aspects (teachers)" and "secondary aspects (students)" to assess the relationship between teachers and students in traditional teaching methods are not rigorous and unscientific. The teaching process is to achieve democracy, teacher-student equality, and requires teachers and students to work together. Teachers should abandon the concept of commanders who are condescending - even teachers who love students and care for students in every possible way. However, if students are not treated as individuals with independent personality and equal freedom, it is impossible to achieve true teacher-student equality. Students should abandon the concept of low self-esteem, objectively and correctly view their independent personality and their relationship with the teacher.

Before using task-driven teaching, the most important preparation is to have a full understanding of the course content, structure, and job requirements. The English course is a basic course for students. Students can master basic listening, speaking, reading and writing skills through study. According to the content and requirements of the course, the course can be divided into several learning modules. When the learning module is confirmed, the teacher is required to understand the curriculum system and the syllabus so that the curriculum can be accurately divided into modules so as to avoid the omission of knowledge and skills. The student learning process is conducted in the form of group learning, and the relevant resources are jointly consulted to solve the problem. Teachers cannot directly tell students how to solve the problems they face or what problems they will encounter, but teachers should provide students with relevant clues to solve the problem, such as what kind of information needs to be collected and where to obtain the relevant information. Information, etc., guide students to analyze and solve problems. At the same time, it advocates discussions and exchanges between students, through the confrontation of different points of view, to supplement, correct, and deepen each student's solution to current problems. Some students, through self-study learning, misunderstood the knowledge content or made mistakes in their skills. As a teacher, in many cases, they will directly provide help and explanations, thus hindering the exploration of students and stifling the students' mistakes. When students understand that there are mistakes and problems in the operation of skills, teachers should be guided to guide students thinking about problems, find problems, and then provide the direction of the solution. Let students find problems in exploration, experience failures and summarize experiences. The teacher's sentence can often allow students to avoid many problems and solve students' problems in understanding. But in this way, students' initiative and enthusiasm for learning are inhibited, and students' ability to analyze and solve problems cannot be cultivated well. 
The assessment is based on the results and processes of self-directed learning. The evaluation includes aspects such as learning attitude, learning thinking, being good at finding help and professionalism. Although teachers do not directly teach knowledge in the classroom, they need to be guided by students' self-learning and group cooperation, complete the task of learning under the guidance of the teacher, and the teacher plays an important role in the learning process. Therefore, teacher evaluations and student suggestions should be added in the classroom. Students should be evaluated in terms of learning effects, classroom management, skill level, classroom guidance, and corrections, etc. to understand the needs and problems of students in the learning process in order to further improve the teaching model.

\section{Effective Strategies of Task Teaching Method Applied in English Teaching in Middle Schools}

Considering that there is a gap in the level of English among students, it is required to consider both the whole and the local in carrying out teaching activities. Students who have a relatively high level of English should be grouped in one group, and those students who are relatively weak in English should be grouped in another. The group develops a study plan based on the actual situation of each group of students. The use of this teaching method can help students to complete tasks in a targeted manner, which can greatly increase the enthusiasm of students to participate, and inspire students' interest in learning while laying a solid foundation for high-quality completion of teaching plans.

The original purpose and purpose of the task-based teaching method is to cultivate students' English application ability, so that they have greater advantages in participating in the process of social competition. Therefore, in the process of carrying out teaching activities, flexible and changeable forms should be adopted, and activities should be avoided as much as possible. Formalization can use forms such as interviewing, buying items, dialogues, and signing contracts. This will not only help students to use English, but also help students understand the actual situation of the students and adjust their teaching plans accordingly. Difficult scenes require students to arrange their homework as much as possible, challenge themselves, and eventually push their English level to a whole new level.

In English teaching in secondary schools, another requirement for students is practical ability. The requirements in the English Curriculum Standards are learning methods of "experience, practice, participation, cooperation, and communication”. It can be seen that the requirements for practical ability are Basic requirements for secondary school students. This requires English teachers in the task setting, we must emphasize the full participation of students, reflecting the students' subjective awareness, help students improve their ability in the task, exercise brain ability, and practice the ability to move. Any source of cognition is derived from practice. Therefore, students' learning ability in practice should be strengthened, language knowledge should be mastered quickly, and understanding should be deepened in order to further use language knowledge. No matter which discipline teachers are, they should help students understand the humanities knowledge and improve the cultural quality. English teachers are certainly not exceptional. This requires teachers to design their tasks not only from the actual situation, but also to introduce students to Chinese and Western cultures. Differences, as well as cultural history, geography and mainstream values in Western culture. These contents should be added to the design of the task so that students can understand the story behind the formation and development of English.

\section{Conclusion}

The traditional teaching model is often taught by teachers and students take lectures as the main form. Students are passive knowledge recipients and do not take into account the students' subjective initiative. This traditional teaching model can hardly produce excellent business secretaries. Therefore, it is necessary to integrate college English into business secretarial English. 
The business secretarial profession not only includes public relations etiquette and document writing, but also includes the basic skills of the secretary and the operation of the office system. Therefore, the combination of college English and business secretarial skills makes business English more practical and applicable.

\section{Acknowledgements}

Hubei Provincial Education Science Plan 2017 Issues Based on cultivating the core literacy of students in the "basic English" classroom teaching strategy research,

Project No.: 2017GB091

\section{References}

[1] Zhao Yiwei. Construction of Cooperative Competition Mechanism in Personalized Situational Teaching for Business English Majors [J]. Shandong Institute of Water Conservancy, 2011, 5(02): 685-686.

[2] Zhou Qi. A Study of the Situational Teaching Model in Business English Teaching [J]. Academic Theory, 2010, 5(30):443-444.

[3] Deng Hua. Strengthening English Teaching Reform in Higher Vocational Colleges and Cultivating Students' Language Application Ability[J].Journal of Shanxi Coal Mining Management Institute,2010,4(01):225-226.

[4] Chen Qinlan, Si Jimao. Business English Teaching and Intercultural Communication Competence [J]. Guangxi Education, 2010, 5(27): 235-236.

[5] Zhang Li. Cultural phenomenon should be paid attention to in the translation teaching of business English [J]. Journal of Bohai University, 2011, 4(01):584-585. 